\title{
Undernutrition among Kenyan children: contribution of child, maternal and household factors
}

\author{
Constance A Gewa ${ }^{1, *}$ and Nanette Yandell ${ }^{2}$ \\ 'Department of Nutrition \& Food Studies, College of Health \& Human Services, George Mason University, \\ 10340 Democracy Lane, MS 1FB, Fairfax, VA 22030, USA: ${ }^{2}$ Department of Global \& Community Health, \\ College of Health \& Human Services, George Mason University, Fairfax, VA, USA
}

Submitted 23 June 2010: Accepted 8 September 2011: First published online 23 November 2011

\begin{abstract}
Objective: To examine the contribution of selected child-, maternal- and householdrelated factors to child undernutrition across two different age groups of Kenyan under-5s.

Design: Demographic and Health Survey data, multistage stratified cluster sampling methodology.

Setting: Rural and urban areas of Kenya.

Subjects: A total of 1851 children between the ages of 0 and 24 months and 1942 children between the ages of 25 and 59 months in Kenya.

Results: Thirty per cent of the younger children were stunted, $13 \%$ were underweight and $8 \%$ were wasted. Forty per cent of the older children were stunted, $17 \%$ were underweight and $4 \%$ were wasted. Longer breast-feeding duration, small birth size, childhood diarrhoea and/or cough, poor maternal nutritional status and urban residence were associated with higher odds of at least one form of undernutrition, while female gender, large birth size, up-to-date immunization, higher maternal age at first birth, BMI and education level at the time of the survey and higher household wealth were each associated with lower odds of at least one form of undernutrition among Kenyan children. The more proximal child factors had the strongest impact on the younger group of children while the intermediate and more distal maternal and household factors had the strongest impact on child undernutrition among the older group of children.

Conclusions: The present analysis identifies determinants of undernutrition among two age groups of Kenyan pre-school children and demonstrates that the contribution of child, maternal and household factors on children's nutritional status varies with children's age.
\end{abstract}

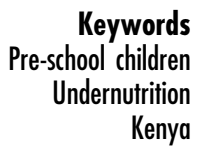

Kenya
Child undernutrition continues to be a problem in Kenya despite a concerted effort by both government and non-government agencies to confront the problem ${ }^{(1,2)}$. The role of child undernutrition in determining child health and development has been acknowledged in various studies. Childhood malnutrition negatively impacts immune function via multiple effects including impaired antibody formation, anatomic barriers and secretory substances, and decreased serum and secretory immunoglobulin among others ${ }^{(3)}$. Over $40-60 \%$ of childhood deaths from diarrhoea, pneumonia, malaria and measles in Africa have been attributed to undernutrition ${ }^{(4)}$ and over $50 \%$ of in-patient hospital admissions and deaths in Kenya were ascribed to malnutrition ${ }^{(5)}$. Early childhood stunting has been associated with long-term cognitive, motor and behavioural deficits including lower levels of intelligence, attention deficits, poor school achievement, impaired fine motor function and social skills, and low work capacity ${ }^{(6,7)}$. While previous research studies have helped to identify a number of determinants of child undernutrition in Kenya and other low-income nations ${ }^{(8-10)}$, most studies often approach the under-5s as a single group of children. This approach in analysis may obscure the role of prospective determinants of malnutrition across different ages of children. Care practices often change with an increasing reliance on and competition for the general household's pool of resources as children grow older. Thus the role of prospective determinants may change with time. The current analysis lends to understanding child malnutrition in Kenya by focusing on both acute and chronic forms of undernutrition and examines the contribution of selected groups of factors on child undernutrition across two different age groups of Kenyan under-5s. 


\section{Participants and methods}

The present analysis utilized data collected from the nationwide Demographic and Health Survey (DHS) in Kenya from April to September 2003. A representative probability sample of almost 10000 households was selected using a multistage stratified cluster sampling methodology in which samples of households within clusters (enumeration areas) are selected ${ }^{(11)}$. This sample was constructed to allow for separate estimates of key indicators for each of the eight provinces in Kenya, as well as for urban and rural areas separately. Urban areas were oversampled and the data have been weighted to cater for the different sample proportions. A total of 400 clusters, 129 urban and 271 rural, were selected from the master frame in the first stage. Households were then systematically selected within each cluster and household residents were eligible to participate in the survey ${ }^{(11)}$. Mothers were the main study respondents, with weights and heights/lengths measured among mothers and all children below 5 years of age. The Kenya DHS experienced high response rates of $96 \%$ among the systematically selected households and 94\% among eligible women of reproductive age. The DHS protocol was approved by ORC Macro's Institutional Review Board.

\section{Weight and length/beight measurements}

Weight and recumbent length or height among all children below 5 years of age and pregnant and nonpregnant women of reproductive age were measured. Anthropometric measurements were taken by trained teams consisting of two interviewers and one health worker. Weight was measured to the nearest $0 \cdot 1 \mathrm{~kg}$ using a lightweight, bathroom-type scales with a digital screen designed and manufactured under the authority of $\mathrm{UNICEF}^{(11)}$. Each participant was measured wearing light clothing without shoes or stockings. Recumbent length was measured for children less than 24 months old and standing height was measured for children 24 months or older. Length/height was measured to the nearest $0 \cdot 1 \mathrm{~cm}$ using a calibrated height board/flexible tape. The measuring boards were specially produced by Shorr Productions (Olney, MD, USA) for use in survey settings. The WHO 2006 growth standards, which use the WHO Multicenter Growth Reference Study (MGRS) population, were used to transform children's weight and length/height measurements into sex- and age-specific $Z$-scores: height-for-age $Z$-score (HAZ), weight-for-age $Z$-score (WAZ) and weight-for-height $Z$-score $(\mathrm{WHZ})^{(12)}$. Weight-for-height $Z$-score was calculated for those with lengths or heights of 65 to $120 \mathrm{~cm}$. Stunting was defined as HAZ below - 2sD, underweight was defined as WAZ below -2SD while wasting was defined as WHZ below $-2 \mathrm{SD}$ from the respective MGRS reference median.

\section{Prospective determinants}

Factors were selected into three main groups: child, maternal and household factors. Child factors were considered to be more proximal and included inherent and more biological factors while maternal and household factors were considered to be more intermediate and distal.

\section{Child factors}

Child's birth size. The child's weight at birth was either recorded from the child's health card or self-reported by the mother. In addition, the mother was asked to indicate the child's size at birth from a range of values: 'very small', 'smaller than average', 'average', 'larger than average' and 'very large'. 'Very small' and 'smaller than average' were pooled into a 'below average' category while 'larger than average' and 'very large' were pooled into an 'above average' category for analysis. Over $53 \%$ of the children had missing information on their birth weight, and so the reported child's size at birth was used in the present analysis. There was a significant positive association between child's birth weight and the subjective measure child's size $(r=0 \cdot 55, P<0 \cdot 0001)$ for records with both birth weight and size at birth. Information was also collected on whether the child was a twin.

Breast-feeding practices. The mother was asked if the child was breast-feeding at the time of the survey and breast-feeding duration was recorded in months.

Immunization. Information on immunization coverage was collected from children's health records and respondents' reports. Specific vaccines included Bacillus Calmette-Guérin (BCG); birth polio, polio I, polio II and polio III; diphtheria-pertussis-tetanus (DPT) I, DPT II and DPT III; and measles vaccine. An indicator of completion of age-specific immunization was created based on the recommended immunization schedule for infants in developing countries ${ }^{(13)}$.

Morbidity experience. The mother was asked to recall if the child had experienced any diarrhoea or cough episode in the previous $24 \mathrm{~h}$ or within the two weeks preceding the interview.

\section{Maternal factors}

Maternal nutritional status. Non-pregnant mothers' BMI was computed as weight in kilograms divided by the square of height in metres. BMI cut-offs were based on the recommended cut-offs as follows: underweight was defined as BMI $<18.5 \mathrm{~kg} / \mathrm{m}^{2}$, normal body weight as BMI of 18.5 to $24.9 \mathrm{~kg} / \mathrm{m}^{2}$, overweight as BMI of 25.0 to $29.9 \mathrm{~kg} / \mathrm{m}^{2}$ and obese was defined as BMI of $30 \cdot 0 \mathrm{~kg} / \mathrm{m}^{2}$ and above. In addition, a maternal height cut-off of $150 \mathrm{~cm}$ was used to categorize mothers into two groups based on height.

Maternal education. Information was collected on the highest level of education attained by the mother. Education levels included no school/pre-school, primary school, secondary school and post-secondary. 


\section{Housebold factors}

Housebold wealth index. The DHS household wealth index was utilized as the indicator of socio-economic status ${ }^{(11)}$. Information on household assets was collected; each asset was assigned a factor score generated through principal components analysis, and the resulting asset scores were standardized in relation to a normal distribution with a mean of zero and standard deviation of one. Each household was then assigned a score for each asset, and the scores were summed for each household. The sample was then divided into quintiles from one (lowest) to five (highest) ${ }^{(11)}$.

Housebold residence. Information on place of residence was indicated as either rural or urban.

The analyses controlled for child's age and sex. Child's age was recorded in months while mother's age was recorded in years.

\section{Statistical analysis}

A total of 5890 children of pre-school age were included in the DHS. Complete sets of weight and height measurements were available for $79 \%$ (4640 out of 5890) of all pre-school children ( $0-5$ years old) included in the survey. A decision was made to exclude twins from the analysis. Children whose mothers were pregnant at the time of the study were also excluded because it was not possible to separate fetal weight from mothers' weight during pregnancy. A total of 578 children were excluded as a result of being a twin ( $n$ 118), mother's pregnancy at the time of the survey ( $n$ 452) or both ( $n$ 8), leaving 4062 pre-school children from 2960 households. Because of the recommendation that breast-feeding continues until 2 years of age or beyond, the 2 year point was used to create the two groups of children $^{(14)}$. A total of 1909 children from 1851 households were aged $\leq 24$ months. Only the youngest child within each household was included in the analyses, which makes up $97 \%$ (1851 out of 1909) of eligible 0-24month-old pre-school children in the DHS. A total of 2153 children from 1942 households were aged $>24$ months. Only the youngest child within this age group from each household was included in the analyses, making up 90\% (1942 out of 2153) of eligible 24-60-month-old pre-school children in the DHS. Altogether, 82\% (3793 out of 4640) of the children with weight and height measurements were included the present analysis.
The SAS statistical software package version 9·1 (SAS Institute, Cary, NC, USA) was used for data analysis. Survey analysis procedures are appropriate for complex survey study designs and were utilized to help estimate sampling errors. SAS procedures SURVEYFREQ, SURVEYMEANS and SURVEYLOGISTIC were used to estimate means, percentages and odds ratios, respectively. There was a high correlation between child's age and breast-feeding duration for the younger group of children $(r=0.94$, $P<0 \cdot 0001)$ and a decision was made to exclude age from the younger group's multiple regression analysis. Bivariate logistic regression was used to assess the association between each factor and the outcome variables: stunting, underweight and wasting. Significant factors were included in the multivariate regression analysis. Separate multiple regression models were used to assess the association between each group of factors (child, maternal and household) and nutritional status. Finally all factors were included in a fully-adjusted regression model.

\section{Results}

The younger children's mean age was $11 \cdot 2(\mathrm{SD} \quad 0 \cdot 2)$ months. Fifty per cent of the children were girls and $84 \%$ lived in rural areas. There were no significant differences in children's ages across gender or between places of residence. The number of children living within the households ranged from one to ten, with a median of three. Overall, $29 \%$ of the younger children were stunted, $13 \%$ underweight and $8 \%$ were wasted (Table 1). Among the older group of children, mean age was $40 \cdot 8(\mathrm{SD} 0 \cdot 2)$ months. Forty-eight per cent of the children were girls and $83 \%$ lived in rural areas. The number of children living within the households ranged from one to ten with a median of three. There were no significant differences in children's ages across gender. Children in the rural areas were slightly older than those in the urban areas ( $41 \cdot 0$ (sD $0 \cdot 3$ ) years $v \cdot 40 \cdot 0$ (sD $0 \cdot 6$ ) years, $P=0 \cdot 04$ ). Overall, $39 \%$ of the older children were stunted, $17 \%$ underweight and $4 \%$ were wasted (Table 1 ).

A majority of the younger children were still breastfeeding with only $10 \%$ weaned from breast milk. There were statistically significant differences in selected characteristics between the well-nourished and undernourished children,

Table 1 Prevalence of undernutrition among Kenyan pre-school children by age group: Demographic and Health Survey data, Kenya, 2003

\begin{tabular}{|c|c|c|c|c|c|c|c|c|c|c|c|c|}
\hline & \multicolumn{4}{|c|}{ Stunted } & \multicolumn{4}{|c|}{ Underweight } & \multicolumn{4}{|c|}{ Wasted } \\
\hline & \multicolumn{2}{|c|}{$\begin{array}{l}\text { 0-24 months } \\
(n \text { 1851) }\end{array}$} & \multicolumn{2}{|c|}{$\begin{array}{l}\text { 25-59 months } \\
(n 1942)\end{array}$} & \multicolumn{2}{|c|}{$\begin{array}{l}\text { 0-24 months } \\
\text { (n 1851) }\end{array}$} & \multicolumn{2}{|c|}{$\begin{array}{l}\text { 25-59 months } \\
(n 1942)\end{array}$} & \multicolumn{2}{|c|}{$\begin{array}{l}\text { 0-24 months } \\
(n \text { 1851) }\end{array}$} & \multicolumn{2}{|c|}{$\begin{array}{l}25-59 \text { months } \\
\text { (n 1942) }\end{array}$} \\
\hline & $\%$ & $95 \% \mathrm{Cl}$ & $\%$ & $95 \% \mathrm{Cl}$ & $\%$ & $95 \% \mathrm{Cl}$ & $\%$ & $95 \% \mathrm{Cl}$ & $\%$ & $95 \% \mathrm{Cl}$ & $\%$ & $95 \% \mathrm{Cl}$ \\
\hline$>-1 S D$ & 49 & 46,52 & 30 & 28,32 & 63 & 60,66 & 52 & 49,55 & 78 & 76,80 & 83 & 81,85 \\
\hline$-2 \mathrm{SD}$ to $-1 \mathrm{SD}$ & 23 & 20,25 & 31 & 29,33 & 24 & 22,26 & 31 & 29,33 & 15 & 13,16 & 13 & 12,15 \\
\hline$<-2 \mathrm{SD}$ & 29 & 26,31 & 39 & 36,42 & 13 & 11,15 & 17 & 15,19 & 8 & 6,9 & 4 & 2,5 \\
\hline
\end{tabular}


specifically with respect to child's age and sex, size at birth, immunization status, recent morbidity, breast-feeding duration or status, mother's age at first birth, mother's nutritional status, mother's education level, place of residence, household wealth index and number of children living at home (Table 2). A majority of the older group of children had been weaned off breast milk with only $7 \%$ breast-feeding at the time of the survey. Differences between the undernourished and well-nourished within this age group were similar to those noted among the younger group of children with only two exceptions: stunted children were younger than the non-stunted children, and a higher percentage of stunted and underweight children were still breast-feeding (Table 3).

\section{Child factors}

Birth size, recent morbidity, breast-feeding duration, immunization status and child's sex were each significantly associated with at least one form of child undernutrition. Smaller birth size, compared with average size at birth, was associated with $2 \cdot 13$ (95\% CI $1 \cdot 56,2 \cdot 89)$ odds of stunting and 2.94 (95\% CI $2 \cdot 02,4 \cdot 29)$ odds of underweight among the younger group of children. Having either diarrhoea or cough was associated with 1.52 (95\% CI $1 \cdot 01,2 \cdot 29$ ) odds of being underweight while having both diarrhoea and cough was associated with $1.93(95 \%$ CI $1.28,3 \cdot 02)$ odds of being underweight and 1.86 (95\% CI 1.04, 3.34) odds of being wasted. One month increase in breast-feeding duration was associated with 14 (95\% CI 11, 14) \% and 9 (95\% CI 6, 12) \% increase in odds of stunting and underweight, respectively. On the other hand, being a female child was associated with 0.62 (95\% CI $0 \cdot 48,0 \cdot 80$ ) odds of being stunted, 0.48 odds of being underweight and 0.59 (95\% CI $0 \cdot 41,0 \cdot 87)$ odds of being wasted. Larger birth size, compared with average size at birth, was associated with 0.71 (95\% CI 0.53, 0.94) odds of stunting and having an up-to-date immunization record was associated with $0 \cdot 66(95 \% \mathrm{CI} 0 \cdot 51,0 \cdot 86)$ odds of being stunted and 0.65 (95\% CI $0 \cdot 46,0.93$ ) odds of being underweight. Together, the selected child factors accounted for $21 \%$ of stunting, $14 \%$ of underweight and $3 \%$ of wasting among the younger children. Over three-quarters of the explained variability in stunting was accounted for by breast-feeding duration.

Results for the older group of children were similar to those noted among the younger children with one exception: breast-feeding duration was not significantly associated with child undernutrition in this group. However, those who were breast-feeding at the time of the study had significantly higher odds of being stunted $(\mathrm{OR}=3 \cdot 10 ; 95 \%$ CI $1 \cdot 96,4 \cdot 90)$ and of being underweight $(\mathrm{OR}=2 \cdot 17 ; 95 \% \mathrm{CI} 1 \cdot 24,3 \cdot 79)$. One month increase in children's age was associated with a 2 (95\% CI 1, 3) \% decrease in odds of stunting. The selected child factors accounted for only $8 \%$ of stunting, $7 \%$ of underweight and $5 \%$ of wasting among the older children.

\section{Maternal factors}

Maternal stature, BMI status, age at first birth and education level were each significantly associated with at least one form of child undernutrition. Short maternal stature $(<150 \mathrm{~cm})$ was associated with $1.93(95 \%$ CI $1 \cdot 22,3 \cdot 04)$ odds of stunting while maternal underweight, compared with normal weight, was associated with 1.55 (95\% CI $1 \cdot 09,2 \cdot 22)$ odds of stunting, $1 \cdot 82$ (95\% CI $1 \cdot 26,2 \cdot 62)$ odds of underweight and $2 \cdot 05$ (95\% CI $1 \cdot 31,3 \cdot 21)$ odds of wasting among the younger group of children. On the other hand, maternal overweight, compared with normal weight, was associated with significantly 0.61 (95\% CI $0 \cdot 43,0 \cdot 87$ ) odds childhood stunting, 0.23 (95\% CI 0.09, $0 \cdot 60)$ odds of underweight and $0.43(95 \%$ CI $0 \cdot 19,0 \cdot 96)$ odds of wasting. Delaying a mother's first birth by one year was associated with $7(95 \%$ CI 3, 12) \% lower odds of stunting and 6 (95\% CI 1, 12) \% lower odds of wasting, while having higher levels of education, compared with no education or pre-school level of education, was associated with significantly lower odds of stunting, underweight and wasting. Together, maternal factors accounted for $6 \%$ of stunting, $9 \%$ of underweight and $6 \%$ of wasting among the younger children.

Results for the older group of children were similar to those noted among the younger children with some exceptions: mother's age at first birth was not significantly associated with wasting while maternal overweight was not significantly associated with child stunting and wasting. Maternal obesity was significantly associated with childhood stunting. Maternal factors accounted for a higher variability of undernutrition among the older group of children (11\% of stunting, $12 \%$ of underweight and $11 \%$ of wasting) than they did among the younger children.

\section{Housebold factors}

Among the younger group of children, household wealth index within the third and fifth quintiles, compared with the first quintile, was associated with 0.64 (95\% CI 0.45, 0.91 ) and $0.43(95 \%$ CI $0.26,0.72)$ odds of stunting, respectively. Wealth index within the fourth quintile was associated with $0.52(95 \%$ CI $0 \cdot 31,0 \cdot 87)$ odds of underweight and wasting. Household factors accounted for the least amount of variation in child undernutrition in this age group: $2 \%$ of stunting, $3 \%$ of underweight and $2 \%$ of wasting.

Among the older group of children, living in the urban areas, compared with rural areas, was associated with higher odds of underweight $(\mathrm{OR}=1 \cdot 94 ; 95 \% \mathrm{CI}$ $1 \cdot 30,2 \cdot 88)$ and wasting $(\mathrm{OR}=2 \cdot 84 ; 95 \% \mathrm{CI} 1 \cdot 14,7 \cdot 07)$, while higher household wealth index (second to fifth quintiles) significantly protected from stunting, underweight and wasting. Household factors accounted for $5 \%$ of stunting, $10 \%$ of underweight and $6 \%$ of wasting. Number of children living at home was not significantly associated with undernutrition among the younger and older children. 
Table 2 Health, demographic and socio-economic characteristics among children aged 0-24 months by nutritional statust,ł: Demographic and Health Survey data, Kenya, 2003

\begin{tabular}{|c|c|c|c|c|c|c|c|c|c|c|c|c|c|c|}
\hline & \multicolumn{2}{|c|}{$\begin{array}{c}\text { All } \\
(n 1851)\end{array}$} & \multicolumn{2}{|c|}{$\begin{array}{l}\text { Stunted } \\
(n \text { 498) }\end{array}$} & \multicolumn{2}{|c|}{$\begin{array}{l}\text { Not stunted } \\
(n \text { 1353) }\end{array}$} & \multicolumn{2}{|c|}{$\begin{array}{l}\text { Underweight } \\
\text { (n 230) }\end{array}$} & \multicolumn{2}{|c|}{$\begin{array}{l}\text { Not underweight } \\
\text { ( } n \text { 1621) }\end{array}$} & \multicolumn{2}{|c|}{$\begin{array}{l}\text { Wasted } \\
(n 147)\end{array}$} & \multicolumn{2}{|c|}{$\begin{array}{l}\text { Not wasted } \\
(\text { (n 1704) }\end{array}$} \\
\hline & Est. & $95 \% \mathrm{Cl}$ & Est. & $95 \% \mathrm{Cl}$ & Est. & $95 \% \mathrm{Cl}$ & Est. & $95 \% \mathrm{Cl}$ & Est. & $95 \% \mathrm{Cl}$ & Est. & $95 \% \mathrm{Cl}$ & Est. & $95 \% \mathrm{Cl}$ \\
\hline Child's age (months) $\ddagger$ & $11 \cdot 2$ & $10 \cdot 9,11 \cdot 6$ & $14 \cdot 7 \S$ & $14 \cdot 1,15 \cdot 4$ & $9 \cdot 8$ & $9 \cdot 5,10 \cdot 2$ & $14 \cdot 0 \S$ & $13 \cdot 0,14 \cdot 9$ & $10 \cdot 8$ & $10 \cdot 5,11 \cdot 1$ & $11 \cdot 2$ & $10 \cdot 9,11 \cdot 6$ & $11 \cdot 2$ & $9 \cdot 9,12 \cdot 4$ \\
\hline \multicolumn{15}{|l|}{ Child's sex } \\
\hline \multicolumn{15}{|l|}{ Size at birth\| } \\
\hline Below average & $15 \cdot 0$ & & $22 \cdot 6$ & & $12 \cdot 0$ & & $29 \cdot 8$ & & $12 \cdot 8$ & & $18 \cdot 5$ & & $14 \cdot 8$ & \\
\hline Average & $60 \cdot 9$ & & $58 \cdot 6$ & & $61 \cdot 7$ & & $50 \cdot 9$ & & $62 \cdot 3$ & & $57 \cdot 6$ & & $61 \cdot 1$ & \\
\hline Above average & $24 \cdot 1$ & & $18 \cdot 8$ & & $26 \cdot 3$ & & $19 \cdot 3$ & & $24 \cdot 8$ & & $23 \cdot 9$ & & $24 \cdot 1$ & \\
\hline Up-to-date immunization & $35 \cdot 9$ & & $31 \cdot 6 \S$ & & $37 \cdot 6$ & & $29 \cdot 1 \S$ & & $36 \cdot 9$ & & $29 \cdot 3$ & & $36 \cdot 4$ & \\
\hline \multicolumn{15}{|l|}{ Recent morbidity } \\
\hline Diarrhoea or cough & $40 \cdot 0$ & & $42 \cdot 7$ & & $38 \cdot 9$ & & $44 \cdot 8 \S$ & & $39 \cdot 3$ & & $41 \cdot 1$ & & $39 \cdot 9$ & \\
\hline Diarrhoea and cough & $16 \cdot 3$ & & $17 \cdot 9$ & & $15 \cdot 6$ & & $23 \cdot 8$ & & $15 \cdot 1$ & & $24 \cdot 2 \S$ & & $15 \cdot 6$ & \\
\hline Currently BF & $90 \cdot 6$ & & $87 \cdot 6 \S$ & & $91 \cdot 9$ & & $91 \cdot 4$ & & $90 \cdot 5$ & & $92 \cdot 8$ & & $90 \cdot 5$ & \\
\hline BF duration (months) $\ddagger$ & $10 \cdot 7$ & $10 \cdot 4,11 \cdot 0$ & $14 \cdot 0 \S$ & $13 \cdot 4,14 \cdot 6$ & $9 \cdot 4$ & $9 \cdot 1,9 \cdot 7$ & $13 \cdot 5 \S$ & $12 \cdot 6,14 \cdot 3$ & $10 \cdot 4$ & $10 \cdot 0,10 \cdot 6$ & $10 \cdot 8$ & $9 \cdot 5,12 \cdot 0$ & $10 \cdot 7$ & $10 \cdot 4,11 \cdot 0$ \\
\hline Mother's age at study (years)‡ & $27 \cdot 0$ & $26 \cdot 6,27 \cdot 4$ & $27 \cdot 3$ & $26 \cdot 7,28 \cdot 0$ & $26 \cdot 8$ & $26 \cdot 4,27 \cdot 3$ & $26 \cdot 9$ & $25 \cdot 8,28 \cdot 1$ & $27 \cdot 0$ & $26 \cdot 6,27 \cdot 4$ & $27 \cdot 0$ & $26 \cdot 6,27 \cdot 4$ & $26 \cdot 8$ & $25 \cdot 5,28 \cdot 0$ \\
\hline Mother's age at first birth (years) $\ddagger, \|$ & $19 \cdot 0$ & $18 \cdot 8,19 \cdot 1$ & $18 \cdot 3 \S$ & $18 \cdot 0,18 \cdot 6$ & $19 \cdot 2$ & $19 \cdot 0,19 \cdot 4$ & $18 \cdot 2 \S$ & $17 \cdot 7,18 \cdot 6$ & $19 \cdot 1$ & $18 \cdot 9,19 \cdot 3$ & $19 \cdot 0$ & $18 \cdot 9,19 \cdot 2$ & $18 \cdot .2$ & $17 \cdot 7,18 \cdot 7$ \\
\hline Maternal height $<150 \mathrm{~cm}$ & $7 \cdot 0$ & & $10 \cdot 6 \S$ & & $5 \cdot 5$ & & $8 \cdot 8$ & & $6 \cdot 7$ & & $4 \cdot 2$ & & $7 \cdot 2$ & \\
\hline \multicolumn{15}{|l|}{ Maternal BMI status } \\
\hline Underweight & $13 \cdot 2$ & & $18 \cdot 0$ & & $11 \cdot 2$ & & $24 \cdot 5$ & & $11 \cdot 4$ & & $26 \cdot 6$ & & $12 \cdot 0$ & \\
\hline Normal & $72 \cdot 2$ & & $72 \cdot 7$ & & $72 \cdot 1$ & & $72 \cdot 5$ & & $72 \cdot 2$ & & $68 \cdot 0$ & & $72 \cdot 6$ & \\
\hline Overweight or obese & $14 \cdot 6$ & & $9 \cdot 3$ & & $16 \cdot 7$ & & $3 \cdot 0$ & & $16 \cdot 4$ & & $5 \cdot 4$ & & $15 \cdot 4$ & \\
\hline \multicolumn{15}{|l|}{ Maternal education level } \\
\hline None/Pre-school & $14 \cdot 1$ & & $16 \cdot 6$ & & $13 \cdot 0$ & & $26 \cdot 2$ & & $12 \cdot 2$ & & $26 \cdot 4$ & & $13 \cdot 0$ & \\
\hline Primary school & $65 \cdot 2$ & & $67 \cdot 5$ & & $64 \cdot 3$ & & $64 \cdot 6$ & & $65 \cdot 3$ & & $62 \cdot 4$ & & $65 \cdot 5$ & \\
\hline Secondary/Post-secondary school & $20 \cdot 7$ & & $15 \cdot 9$ & & $22 \cdot 7$ & & $9 \cdot 2$ & & $22 \cdot 5$ & & $11 \cdot 2$ & & $21 \cdot 5$ & \\
\hline \multicolumn{15}{|l|}{ Residence location } \\
\hline Urban & $16 \cdot 4$ & & $13 \cdot 6$ & & $17 \cdot 5$ & & $7 \cdot 9 \S$ & & $17 \cdot 6$ & & $7 \cdot 7 \S$ & & $17 \cdot 1$ & \\
\hline \multicolumn{15}{|l|}{ Wealth index } \\
\hline First quintile & $25 \cdot 4$ & & $31 \cdot 1 \S$ & & $23 \cdot 2$ & & $35 \cdot 3 \S$ & & $24 \cdot 0$ & & $32 \cdot 8 \S$ & & $24 \cdot 8$ & \\
\hline Second quintile & $21 \cdot 7$ & & $23 \cdot 8$ & & $20 \cdot 8$ & & $23 \cdot 4$ & & $21 \cdot 4$ & & $27 \cdot 9$ & & $21 \cdot 1$ & \\
\hline Third quintile & $19 \cdot 7$ & & $17 \cdot 4$ & & $20 \cdot 7$ & & $20 \cdot 4$ & & $19 \cdot 7$ & & $17 \cdot 9$ & & $19 \cdot 9$ & \\
\hline Fourth quintile & $16 \cdot 3$ & & $15 \cdot 6$ & & $16 \cdot 5$ & & $11 \cdot 9$ & & $16 \cdot 9$ & & $10 \cdot 7$ & & $16 \cdot 8$ & \\
\hline Fifth quintile & $16 \cdot 9$ & & $12 \cdot 1$ & & $18 \cdot 8$ & & $9 \cdot 0$ & & $18 \cdot 0$ & & $10 \cdot 7$ & & $17 \cdot 4$ & \\
\hline Number of children at homeł & $2 \cdot 9$ & $2 \cdot 8,3 \cdot 0$ & $3 \cdot 1 \S$ & $2 \cdot 9,3 \cdot 2$ & $2 \cdot 8$ & $2 \cdot 7,2 \cdot 9$ & $3 \cdot 1$ & $2 \cdot 8,3 \cdot 4$ & $2 \cdot 9$ & $2 \cdot 7,3 \cdot 0$ & $3 \cdot 0$ & $2 \cdot 7,3 \cdot 4$ & $2 \cdot 9$ & $2 \cdot 8,3 \cdot 0$ \\
\hline
\end{tabular}

Est., estimate; BF, breast-feeding

Estimates are percentage values unless otherwise indicated.

łEstimates are mean $(95 \% \mathrm{Cl})$ values.

Estimate values were significantly different between nutritional status categories: stunted $v$. not stunted, underweight $v$. not underweight or wasted $v$. not wasted $(P<0 \cdot 05)$.

\|Statistically significant differences in estimate distribution: stunted $v$. not stunted and underweight $v$. not underweight $(P<0.05)$.

- Statistically significant differences in estimate distribution: stunted $v$. not stunted, underweight $v$. not underweight and wasted $v$. not wasted $(P<0.05)$. 
Table 3 Health, demographic and socio-economic characteristics among children aged 25-60 months by nutritional statust,f: Demographic and Health Survey data, Kenya, 2003

\begin{tabular}{|c|c|c|c|c|c|c|c|c|c|c|c|c|c|c|}
\hline & \multicolumn{2}{|c|}{$\begin{array}{c}\text { All } \\
(n \text { 1942) }\end{array}$} & \multicolumn{2}{|c|}{$\begin{array}{l}\text { Stunted } \\
(n 739)\end{array}$} & \multicolumn{2}{|c|}{$\begin{array}{l}\text { Not stunted } \\
(n \text { 1203) }\end{array}$} & \multicolumn{2}{|c|}{$\begin{array}{l}\text { Underweight } \\
\qquad(\text { n 338) }\end{array}$} & \multicolumn{2}{|c|}{$\begin{array}{l}\text { Not underweight } \\
\text { (n 1604) }\end{array}$} & \multicolumn{2}{|c|}{$\begin{array}{l}\text { Wasted } \\
(n 95)\end{array}$} & \multicolumn{2}{|c|}{$\begin{array}{l}\text { Not wasted } \\
(n \text { 1846) }\end{array}$} \\
\hline & Est. & $95 \% \mathrm{Cl}$ & Est. & $95 \% \mathrm{Cl}$ & Est. & $95 \% \mathrm{Cl}$ & Est. & $95 \% \mathrm{Cl}$ & Est. & $95 \% \mathrm{Cl}$ & Est. & $95 \% \mathrm{Cl}$ & Est. & $95 \% \mathrm{Cl}$ \\
\hline $\begin{array}{l}\text { Child's age (months) } \\
\text { Child's sex }\end{array}$ & $40 \cdot 8$ & $40 \cdot 3,41 \cdot 3$ & $39 \cdot 2 \S$ & $38 \cdot 4,39 \cdot 9$ & $41 \cdot 9$ & $41 \cdot 3,42 \cdot 5$ & $40 \cdot 2$ & $39 \cdot 1,41 \cdot 3$ & $41 \cdot 0$ & $40 \cdot 5,41 \cdot 5$ & $40 \cdot 9$ & $38 \cdot 8,43 \cdot 0$ & $40 \cdot 8$ & $40 \cdot 3,41 \cdot 3$ \\
\hline Female & $48 \cdot 3$ & & $43 \cdot 8 \S$ & & $51 \cdot 2$ & & $41 \cdot 7 \S$ & & $49 \cdot 7$ & & $40 \cdot 5 \S$ & & $49 \cdot 3$ & \\
\hline \multicolumn{15}{|l|}{ Size at birth\| } \\
\hline Below average & $15 \cdot 5$ & & $19 \cdot 3$ & & $13 \cdot 1$ & & $25 \cdot 0$ & & $13 \cdot 6$ & & $27 \cdot 4$ & & $15 \cdot 0$ & \\
\hline Average & $59 \cdot 1$ & & $57 \cdot 9$ & & $59 \cdot 8$ & & $60 \cdot 5$ & & $58 \cdot 8$ & & $61 \cdot 2$ & & $59 \cdot 0$ & \\
\hline Above average & $25 \cdot 4$ & & $22 \cdot 8$ & & $27 \cdot 1$ & & $14 \cdot 5$ & & $27 \cdot 6$ & & $11 \cdot 4$ & & $26 \cdot 0$ & \\
\hline Up-to-date immunization & $38 \cdot 6$ & & $33 \cdot 8 \S$ & & $41 \cdot 6$ & & $33 \cdot 2$ & & $39 \cdot 7$ & & $30 \cdot 0$ & & $38 \cdot 9$ & \\
\hline \multicolumn{15}{|l|}{ Recent morbidity } \\
\hline Diarrhoea or cough & $40 \cdot 0$ & & $41 \cdot 2 \S$ & & $39 \cdot 3$ & & $42 \cdot 6 \S$ & & $39 \cdot 5$ & & $32 \cdot 6 \S$ & & $40 \cdot 3$ & \\
\hline Diarrhoea and cough & $5 \cdot 4$ & & $7 \cdot 1$ & & $4 \cdot 2$ & & $8 \cdot 4$ & & $4 \cdot 7$ & & $9 \cdot 3$ & & $5 \cdot 2$ & \\
\hline Currently BF & $7 \cdot 1$ & & $12 \cdot 7 \S$ & & $3 \cdot 5$ & & $13 \cdot 1 \S$ & & $5 \cdot 9$ & & $10 \cdot 9$ & & $6 \cdot 9$ & \\
\hline BF duration (months) $\ddagger$ & $20 \cdot 0$ & $19 \cdot 9,20 \cdot 3$ & $20 \cdot 3$ & $19 \cdot 7,20 \cdot 9$ & $19 \cdot 8$ & $19 \cdot 2,20 \cdot 3$ & $20 \cdot 6$ & $19 \cdot 6,21 \cdot 5$ & $19 \cdot 8$ & $19 \cdot 2,20 \cdot 2$ & $19 \cdot 9$ & $17 \cdot 3,22 \cdot 5$ & $20 \cdot 0$ & $19 \cdot 6,20 \cdot 3$ \\
\hline Mother's age at study (years)‡ & $29 \cdot 8$ & $29 \cdot 4,30 \cdot 1$ & $29 \cdot 5$ & $29 \cdot 0,30 \cdot 0$ & $29 \cdot 9$ & $29 \cdot 5,30 \cdot 4$ & $29 \cdot 6$ & $28 \cdot 8,30 \cdot 3$ & $29 \cdot 8$ & $29 \cdot 4,30 \cdot 2$ & $29 \cdot 6$ & $28 \cdot 1,31 \cdot 1$ & $29 \cdot 7$ & $29 \cdot 4,30 \cdot 2$ \\
\hline Mother's age at first birth (years)‡,\| & $19 \cdot 1$ & $19 \cdot 0,19 \cdot 3$ & $18 \cdot 6 \S$ & $18 \cdot 4,18 \cdot 8$ & $19 \cdot 4$ & $19 \cdot 2,19 \cdot 7$ & $18 \cdot 5$ & $18 \cdot 1,18 \cdot 8$ & $19 \cdot 3$ & $19 \cdot 1,19 \cdot 4$ & $19 \cdot 1$ & $18 \cdot 3,19 \cdot 9$ & $19 \cdot 1$ & $19 \cdot 0,19 \cdot 3$ \\
\hline Maternal height $<150 \mathrm{~cm}$ & $6 \cdot 3$ & & $10 \cdot 5 \S$ & & $3 \cdot 6$ & & $8 \cdot 7$ & & $5 \cdot 9$ & & $4 \cdot 5$ & & $6 \cdot 4$ & \\
\hline \multicolumn{15}{|l|}{ Maternal BMI status } \\
\hline Underweight & $12 \cdot 4$ & & $15 \cdot 7$ & & $10 \cdot 3$ & & $23 \cdot 1$ & & $10 \cdot 3$ & & $31 \cdot 7$ & & $11 \cdot 7$ & \\
\hline Normal & $67 \cdot 9$ & & $72 \cdot 3$ & & $65 \cdot 0$ & & $68 \cdot 9$ & & $67 \cdot 7$ & & $55 \cdot 0$ & & $63 \cdot 4$ & \\
\hline Overweight or obese & $19 \cdot 7$ & & $12 \cdot 0$ & & $24 \cdot 7$ & & $8 \cdot 0$ & & $22 \cdot 1$ & & $13 \cdot 3$ & & $19 \cdot 9$ & \\
\hline \multicolumn{15}{|l|}{ Maternal education level } \\
\hline None/Pre-school & $13 \cdot 7$ & & $17 \cdot 0$ & & $11 \cdot 6$ & & $27 \cdot 8$ & & $10 \cdot 9$ & & $45 \cdot 6$ & & $12 \cdot 4$ & \\
\hline Primary school & $62 \cdot 3$ & & $70 \cdot 3$ & & $57 \cdot 2$ & & $62 \cdot 8$ & & $62 \cdot 2$ & & $37 \cdot 7$ & & $63 \cdot 3$ & \\
\hline Secondary/Post-secondary school & $24 \cdot 0$ & & $12 \cdot 7$ & & $31 \cdot 2$ & & $9 \cdot 4$ & & $26 \cdot 9$ & & $16 \cdot 7$ & & $24 \cdot 3$ & \\
\hline \multicolumn{15}{|l|}{ Residence location } \\
\hline Urban & $16 \cdot 8$ & & $13 \cdot 7 \S$ & & $18 \cdot 8$ & & $10 \cdot 3 \S$ & & $18 \cdot 1$ & & $17 \cdot 7 \S$ & & $16 \cdot 8$ & \\
\hline \multicolumn{15}{|l|}{ Wealth index } \\
\hline First quintile & $23 \cdot 6$ & & $30 \cdot 9 \S$ & & $19 \cdot 1$ & & $43 \cdot 3 \S$ & & $19 \cdot 7$ & & $44 \cdot 7 \S$ & & $22 \cdot 8$ & \\
\hline Second quintile & $22 \cdot 0$ & & $23 \cdot 7^{\circ}$ & & $20 \cdot 9$ & & $24 \cdot 0$ & & $21 \cdot 6$ & & $22 \cdot 6$ & & $22 \cdot 0$ & \\
\hline Third quintile & $19 \cdot 4$ & & $18 \cdot 7$ & & $19 \cdot 8$ & & $14 \cdot 9$ & & $20 \cdot 3$ & & $5 \cdot 1$ & & $20 \cdot 0$ & \\
\hline Fourth quintile & $18 \cdot 0$ & & $15 \cdot 6$ & & $19 \cdot 5$ & & $12 \cdot 7$ & & $19 \cdot 0$ & & $18 \cdot 2$ & & $17 \cdot 9$ & \\
\hline Fifth quintile & $17 \cdot 0$ & & $11 \cdot 1$ & & $20 \cdot 7$ & & $5 \cdot 1$ & & $19 \cdot 4$ & & $9 \cdot 4$ & & $17 \cdot 3$ & \\
\hline Number of children at homeł & $3 \cdot 4$ & $3 \cdot 3,3 \cdot 5$ & $3 \cdot 6 \S$ & $3 \cdot 4,3 \cdot 7$ & $3 \cdot 2$ & $3 \cdot 1,3 \cdot 4$ & $3 \cdot 8 \S$ & $3 \cdot 5,4 \cdot 0$ & $3 \cdot 3$ & $3 \cdot 2,3 \cdot 4$ & $3 \cdot 7$ & $3 \cdot 3,4 \cdot 1$ & $3 \cdot 3$ & $3 \cdot 2,3 \cdot 4$ \\
\hline
\end{tabular}

Est., estimate; BF, breast-feeding.

Estimates are percentage values unless otherwise indicated.

\#Estimates are mean $(95 \% \mathrm{Cl})$ values.

Estimate values were significantly different between nutritional status categories: stunted $v$. not stunted, underweight $v$. not underweight or wasted $v$. not wasted $(P<0 \cdot 05)$.

$\|$ Statistically significant differences in estimate distribution: stunted $v$. not stunted and underweight $v$. not underweight $(P<0.05)$.

- Statistically significant differences in estimate distribution: stunted $v$. not stunted, underweight $v$. not underweight and wasted $v$. not wasted $(P<0.05)$. 


\section{Child, maternal and housebold factors}

Most variables retained statistical significance when included in one regression model (Table 4). The only exception was that none of the household factors predicted any form of childhood undernutrition among the younger group of children.

\section{Discussion}

The current analysis documents the presence of high levels of undernutrition among children in Kenya and demonstrates that the contribution of child, maternal and household factors to undernutrition varies across the early and late 'under-5' period. Prevalence of undernutrition was comparable to that reported in an earlier nationwide study carried out among 6-72-month-old children ${ }^{(15)}$. On average, $37 \%$ of the children were stunted indicating that stunting levels have not changed in over a decade. Underweight seems to have reduced over the years from $27 \%$ in 1999 to $13-17 \%$ in the current analysis. Wasting prevalence seems to have remained constant.

Our results show that the male children are disadvantaged across all three forms of undernutrition. Male vulnerability may arise from biological and inherent factors and environmental factors. Wells argues that natural selection may not favour male offspring survival compared with female offspring survival, especially in poor environments, thus leading to increased male vulnerability especially during early childhood years ${ }^{(16)}$. Reports of higher undernutrition prevalence among male children compared with female children have been documented in a number of Sub-Saharan African nations ${ }^{(17,18)}$. Other cultural or behavioural factors may also influence the male:female malnutrition ratio. Care-giving practices have been shown to influence children's nutritional status ${ }^{(19)}$ and the gender-based differences may be a result of the type of care provided to the female $v$. the male children. Although no gender-based differences were reported in infant care among the Kipsigis tribe in Kenya ${ }^{(20)}$, a study that assessed gender roles in Kenyan television commercials showed that Kenyan women were depicted to be more involved in domestic and food-related chores unlike men who were more involved in non-domestic outdoor activities ${ }^{(21)}$. In light of this depiction, female children may be spending more time with mothers and other caregivers, thus receiving more attention, while the male children may be spending more time out of the house, playing with other male children away from food preparation and with greater energy expenditure.

Children's birth weight has been shown to have an impact on growth in general. Low-birth-weight (LBW) children experience smaller increments in height and weight and remain shorter and lighter with a higher percentage being stunted, underweight or wasted ${ }^{(22-25)}$. This is especially true for LBW children born and raised in poor environments characterized by low socio-economic status, poor maternal nutritional status and high morbidity risk, and inhibits length and weight gains among LBW infants $^{(26)}$. Our results show this impact of birth size on stunting, underweight and wasting among younger and older children.

Up-to-date immunization was associated with lower odds of stunting and underweight among the younger children and lower odds of stunting among the older children. Complete immunization status has been associated with lower levels of morbidity and mortality among children $^{(27)}$. In addition, up-to-date immunization may reflect access to health-care services and contact with health personnel and advice, leading to better nutritional outcomes for children or a higher level of health awareness among caregivers ${ }^{(28,29)}$. Required vaccines in lessindustrialized countries are scheduled to be completed within the first 9 months of life and may reflect a mix of short- and long-term disease occurrence/protection depending on the child's age. For the oldest children in the analysis, up-to-date immunization status may reflect long-term disease occurrence/protection and have an association with a chronic undernutrition measure such as stunting, while for the younger children it may reflect a mix of short- and long-term disease occurrence depending on the child's age, thus impacting both chronic and acute measures of undernutrition. Children who had suffered from diarrhoea and/or coughs had higher undernutrition, with odds of growth deficits being higher among those reported to have both infections. Infections such as diarrhoea and respiratory tract infections have been associated with reduced food intake and increased nutrient losses, resulting in poor nutrition and growth among children $^{(30)}$. Our use of indicators of recent morbidity may explain noted association between the morbidity indicators and the more acute measures, underweight and wasting.

Longer breast-feeding duration was associated with higher odds of stunting and underweight among the younger group of children. Among older children, breastfeeding at the time of the survey was associated with higher odds of stunting. Such negative association may be due to reverse causality, where mothers choose to favour longer breast-feeding durations if their children are experiencing poor growth ${ }^{(31-33)}$. The negative association could also result from poor quality or untimely introduction of non-breast-milk foods leading to inadequate growth over time. Non-breast-milk diet diversity is essential for adequate growth among children ${ }^{(34)}$. Depending on the age of the child, the relationship between breast-feeding and undernutrition may reflect current or ongoing chronic deprivation. One of the limitations of the current analysis is the lack of information on other dietary practices including the weaning age and children's food types and amounts. Thus we were not able to account for this critical information that might have helped provide a better understanding of the results 
Table 4 Relationship between childhood undernutrition and child, maternal and household factorst: Demographic and Health Survey data, Kenya, 2003

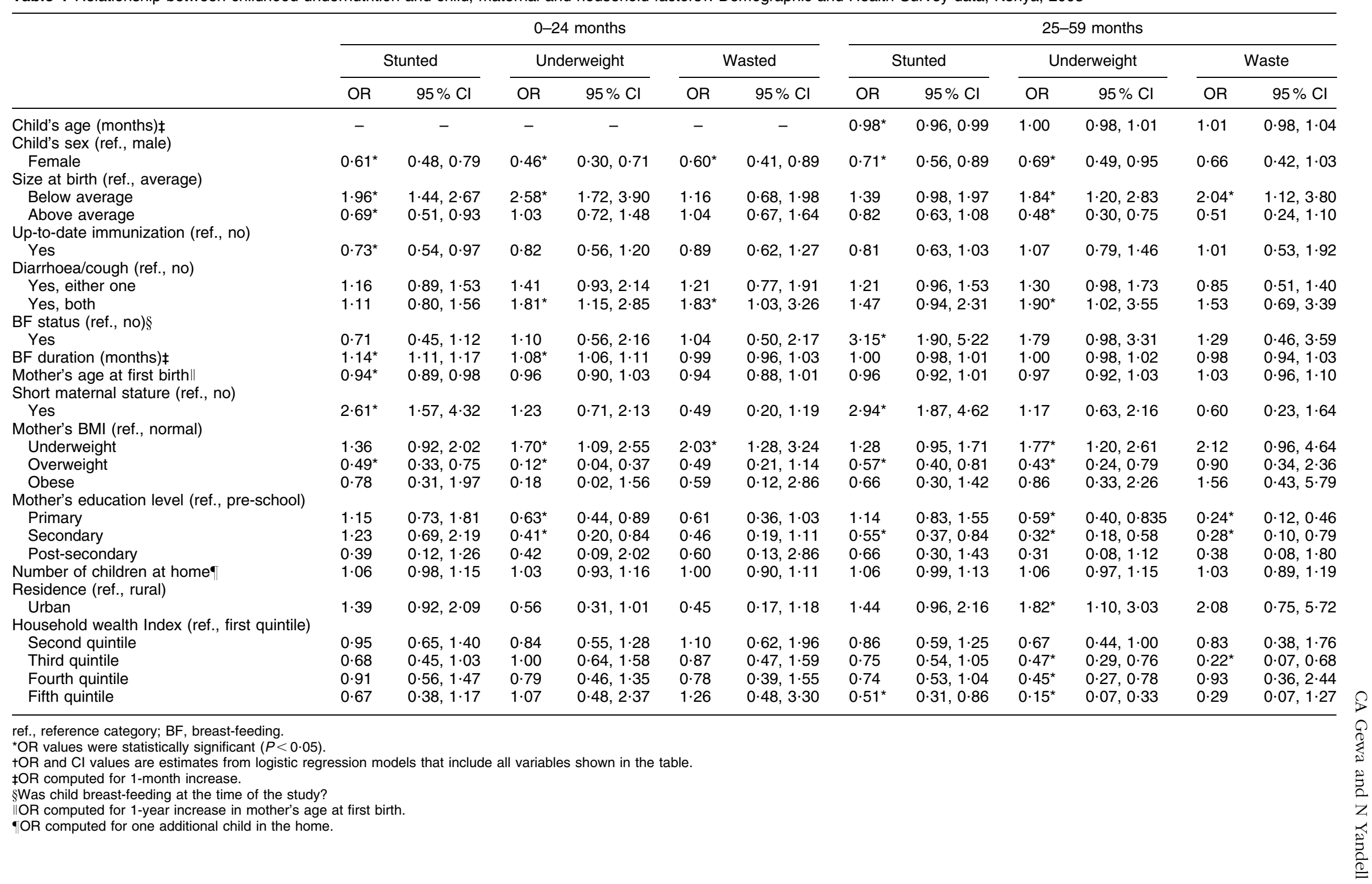


related to breast-feeding. The study design by nature did not follow the children's growth over time to help elucidate the relationship between breast-feeding duration and child growth.

Being a younger mother at first birth was associated with higher odds of childhood stunting and underweight among the younger group of children and stunting among the older children. The significant association between maternal age at first birth and stunting among the younger children was maintained in the final regression model. Women who become pregnant at a younger age have been noted to have inadequate nutritional status, which often leads to poor nutritional status among their children ${ }^{(35)}$. The significant association between maternal nutritional status (stature and BMI status) and child nutritional status could be a result of genetic and/or environmental factors. A shared environment that is lacking in adequate nutrition will affect parents and children in a similar manner, leading to inadequate growth and development ${ }^{(36)}$. Thus a deficient environment is associated with current and ongoing exposure to nutritional deficiencies, resulting in inadequate gains in stature and body weight. Parental height has been shown to be negatively associated with a stunting among children $^{(22,37-39)}$.

Results on maternal education and household wealth and child nutrition are congruent with those of other studies $^{(10,22,40)}$. Maternal education and household wealth are associated with multiple positive factors including increased access to food and health-care resources ${ }^{(41)}$. Household wealth, education and residence are indicators of socio-economic status and are expected to reflect both current and ongoing access to resources. These measures are shown to be significantly associated with stunting, underweight and wasting among younger and older children in our results. However, the relationship between household socio-economic status and undernutrition was more noticeable and consistent among the older children. The high levels of undernutrition in urban areas might be attributed to the rise in poverty and informal settlements in urban areas ${ }^{(42-44)}$.

The current analysis adds to the understanding of the contribution of various determinants of acute and chronic forms of undernutrition among children of non-pregnant women in Kenya. The impact of the proximal, biological or inherent factors (all child factors and maternal height and age at first birth) on child nutritional status may persist across various age groups. On the other hand, the more distal socio-economic status and environmental factors may show a stronger impact on child nutritional status as children grow older and come in direct contact and competition for household-care resources, including food and access to health-care services. Our analysis showed a strong impact of child factors on the younger children's nutritional status. Although some of the biological and inherent factors were significantly associated with undernutrition among the older children, their overall ability to explain the undernutrition variability in this age group was diminished. The impact of household socioeconomic and environmental factors was highest on the older children's nutritional status and accounted for a larger proportion of the undernutrition variability noted in this age group.

\section{Acknowledgements}

Source of funding: This research received no specific grant from any funding agency in the public, commercial or not-for-profit sectors. Conflict of interest declaration: None. Authorship responsibilities: C.A.G. was responsible for data analysis. Both C.A.G. and N.Y. were responsible for the writing of this paper. Acknowledgements: The authors acknowledge ORC Macro for making the DHS data available, and Dr Heibatollah Baghi and Dr Kathryn Jacobsen for guidance on statistical analysis.

\section{References}

1. Bryce J, Coitinho D, Darnton-Hill I et al. (2008) Maternal and child undernutrition: effective action at national level. Lancet 371, 454-455.

2. Demographic and Health Survey (2003) Kenya Standard DHS Final Report. http://www.measuredhs.com/countries/ country_main.cfm?ctry_id $=20 \& c=$ Kenya $($ accessed November 2009).

3. Scrimshaw NS \& SanGiovanni JL (1997) Synergism of malnutrition, infection and immunity: an overview. $A m J$ Clin Nutr 66, issue 2, 464S-477S.

4. Caulfield LE, de Onis M, Blössner M et al. (2004) Undernutrition as an underlying cause of child deaths associated with diarrhea, pneumonia, malaria, and measles. Am J Clin Nutr 80, 193-198.

5. Bejon P, Mohammed S, Mwangi I et al. (2008) Fraction of all hospital admissions and deaths attributable to malnutrition among children in rural Kenya. Am J Clin Nutr 88, 1626-1631.

6. Martorell R (1999) The nature of child malnutrition and its long-term implications. Food Nutr Bull 20, 288-292.

7. Grantham-McGregor S \& Baker-Henningham H (2005) Review of the evidence linking protein and energy to mental development. Public Health Nutr 8, 1191-1201.

8. Neumann CG \& Harrison GG (1999) Onset and evolution of stunting in infants and children. Examples from the Human Nutrition Collaborative Research Support Program. Kenya and Egypt studies. Eur J Clin Nutr 48, Suppl. 1, S90-S102.

9. Kabuba-Mariara J, Ndenge GK \& Mwabu DK (2008) Determinants of children's nutritional status in Kenya: evidence from demographic and health surveys. J Afr Econ 18, 363-387.

10. Deolaliker AB (1998) Child nutritional status and child growth in Kenya: socioeconomic determinants. J Int Dev $\mathbf{8}$, 375-392.

11. Central Bureau of Statistics (2004) Kenya Demographic and Health Survey 2003. Nairobi \& Calverton, MD: CBS/Kenya Ministry of Health \& ORC Macro.

12. World Health Organization (2007) WHO Anthro for Personal Computers Manual. Software for Assessing Growth and Development of the World's Children. Geneva: WHO. 
13. World Health Organization (2003) State of World's Vaccines and Immunizations. Geneva: WHO.

14. Kramer MS \& Kakuma R (2001) The Optimal Duration of Exclusive Breastfeeding: A Systematic Review. Geneva: WHO; available at http://whqlibdoc.who.int/hq/2001/ WHO_NHD_01.08.pdf

15. Ngare DK \& Muttunga JN (1999) Prevalence of malnutrition in Kenya. East Afr Med J 76, 376-380.

16. Wells JCK (2000) Natural selection and sex differences in morbidity and mortality in early life. J Theor Biol 202, 65-76.

17. Espo M, Kulmala T, Maleta K et al. (2002) Determinants of linear growth and predictors of severe stunting during infancy in rural Malawi. Acta Paediatr 91, $1365-1370$.

18. Wamani H, Astrom AN, Peterson S et al. (2007) Boys are more stunted than girls in Sub-Saharan Africa: a metaanalysis of 16 demographic and health surveys. BMC Pediatr 7, 17.

19. Begin F, Frongillo EA \& Delisle H (1999) Caregiver behaviors and resources influence child height-for-age in rural Chad. J Nutr 129, 680-686.

20. Mulder MB \& Milton M (1985) Factors affecting infant care in the Kipsigis. J Anthropol Res 41, 231-262.

21. Mwangi MW (1996) Gender roles portrayed in Kenyan television commercials. Sex Roles 34, 205-214.

22. Arifeen SE, Black RE, Caulfield LE et al. (2001) Determinants of infant growth in the slums of Dhaka: size and maturity at birth, breastfeeding and morbidity. Eur J Clin Nutr 55, 167-178.

23. Binkin NJ, Yip R, Fleshood L et al. (1988) Birth weight and childhood growth. Pediatrics 82, 828-834.

24. Adair LS \& Guilkey DK (1997) Age-specific determinants of stunting in Filipino children. J Nutr 127, 314-320.

25. Adair LS (1999) Filipino children exhibit catch-up growth from age 2 to 12 years. J Nutr 129, 1140-1148.

26. Ashworth A, Morris SS \& Lira PIC (1997) Postnatal growth patterns of full-term low birth weight infants in Northeast Brazil are related to socioeconomic status. J Nutr $\mathbf{1 2 7}$, 1950-1956.

27. Semba RD, de Pee S, Derger SG et al. (2007) Malnutrition and infectious disease morbidity among children missed by the childhood immunization program in Indonesia. $S E$ Asian J Trop Med Public Health 38, 120-129.

28. Ahmed HM, Mitchell M \& Bethany H (2010) National implementation of Integrated Management of Childhood Illness (IMCI): policy constraints and strategies. Health Policy 96, 128-133.

29. Toikilik S, Tuges G, Lagani J et al. (2010) Are hard-to-reach populations being reached with immunization services? Findings from Papua New Guinea national immunization coverage survey. Vaccine 28, 4673-4679.
30. Semba RD \& Bloem MW (editors) (2008) Nutrition and Health in Developing Countries, 2nd ed. New York, NY: Humana Press.

31. Marquis GS, Habicht JP, Lanata CF et al. (1997) Association of breastfeeding and stunting in Peruvian toddlers: an example of reverse causality. Int J Epidemiol 26, 349-356.

32. Simondon KB \& Simondon F (1998) Mothers prolong breastfeeding of undernourished children in rural Senegal. Int J Epidemiol 27, 490-494.

33. Fawzi WW, Herrera MG, Nestel P et al. (1998) A longitudinal study of prolonged breastfeeding in relation to child undernutrition. Int J Epidemiol 27, 255-260.

34. Onyango A, Koski KG \& Tucker K (1998) Food diversity versus breast feeding choice in determining anthropometric status in rural Kenyan toddlers. Int J Epidemiol 27, 484-489.

35. UNICEF (2000) League table: Stunting in children under age 5. http://www.unicef.org/pon00/leaguetos1.htm (accessed April 2010).

36. Ulijaszek SJ (1996) Relationship between undernutrition, infection, and growth and development. Hum Evol 11, 233-248.

37. Zottarelli LK, Sunil TS \& Rajaram S (2007) Influence of parental and socioeconomic factors on stunting in children under 5 years in Egypt. East Mediterr Health J 13, 1330-1342.

38. Varela-Silva MI, Azocrra H, Dickinson F et al. (2009) Influence of maternal stature, pregnancy age, and infant birth weight on growth during childhood in Yucatan, Mexico: a test of the intergenerational effects hypothesis. Am J Hum Biol 21, 657-663.

39. Ozaltin E, Hill K \& Subramanian SV (2010) Association of maternal stature with offspring mortality, underweight, and stunting in low- to middle-income countries. JAMA $\mathbf{3 0 3}$, 1507-1516.

40. Engebretsen IMS, Tylleskär T, Wamani H et al. (2008) Determinants of infant growth in Eastern Uganda: a community-based cross-sectional study. BMC Public Health 8, 418.

41. Caldwell J \& McDonald P (1982) Influence of maternal education on infant and child mortality: levels and causes. Health Policy Educ 2, 251-267.

42. Muoki MA, Tumuti DS \& Rombo GO (2008) Nutrition and public hygiene among children under five yeas of age in Mukuru slums of Makadara division, Nairobi. East Afr MedJ 85, 386-397.

43. Thuita FM, Mwadime RKN \& Wang'ombe JK (2005) Child nutritional status and maternal factors in an urban slum in Nairobi, Kenya. East Afr Med J 82, 209-215.

44. Odhiambo WM \& Manda DK (2003) Urban poverty and labour force participation in Kenya. World Bank Urban Research Symposium, Washington, DC, 15-17 December. http://siteresources.worldbank.org/INTGENDER/Resources/ UrbanpovertyLaborForce.pdf (accessed April 2010). 